\title{
Gauging the ungauged basin: a top-down approach in a large semiarid watershed in China
}

\author{
F. K. Barthold ${ }^{1}$, T. Sayama ${ }^{2}$, K. Schneider ${ }^{1}$, L. Breuer ${ }^{1}$, K. B. Vaché $^{1}$, H.-G. Frede ${ }^{1}$, and J. J. McDonnell ${ }^{2}$ \\ ${ }^{1}$ Institute for Landscape Ecology and Resources Management, Justus-Liebig-University Giessen, Germany \\ ${ }^{2}$ Department of Forest Engineering, Oregon State University, Corvallis, USA
}

Received: 18 January 2008 - Revised: 20 March 2008 - Accepted: 28 May 2008 - Published: 20 June 2008

\begin{abstract}
A major research challenge in ungauged basins is to quickly assess the dominant hydrological processes of watersheds. In this paper we present a top-down approach from first field reconnaissance to perceptual model development, model conceptualization, evaluation, rejection and eventually, to a more substantial field campaign to build upon the initial modeling. This approach led us from an initial state where very little was known about catchment behavior towards a more complete view of catchment hydrological processes, including the preliminary identification of water sources and an assessment of the effectiveness of our sampling design.
\end{abstract}

\section{Introduction}

Gauging the ungauged basin is a major research challenge, in part so because we currently lack tools to quickly diagnose the dominant processes of watersheds for use in conceptual model development and prediction (Sivapalan, 2003). Usually, long-term datasets of hydrometric and hydrochemical information are needed to begin an evaluation of dominant runoff producing processes, however, in many catchments, these data are not available.

Conceptual models have a set of traits that can be advantageous in the rapid identification of runoff generating processes. They (1) can capture processes at the catchment scale (2) offer the potential of model development using information on age, origin and pathway of surface and subsurface storm flow, (3) can utilize known physical parameters, and (4) allow identification of parameters values through calibration against runoff (Seibert and McDonnell, 2002). Conceptual models that treat volume-based mixing and mass balance

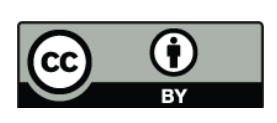

Correspondence to: F. K. Barthold (frauke.barthold@umwelt.unigiessen.de) are useful for streamflow modeling with geochemical dimension. Combining conceptual models and data from first field reconnaissance is an approach to begin the development of a more complete understanding of hydrological processes in previously ungauged basins.

In this study we follow a road map (Fig. 1) for how one might start the process in a large, ungauged basin in Inner Mongolia, with identification of simple hydrological patterns as a first step in predicting flow in this data sparse region. We designed this process as a top-down approach, as initially introduced by Klemeš (1983), consisting of the following five steps:

1. Field reconnaissance and data collection,

2. Perceptual model development,

3. Reservoir model conceptualization,

4. Evaluation with hydrochemical data and

5. Complete field campaign (Fig. 1).

The objective of this study is to use geochemistry-based field reconnaissance to assess dominant processes of water cycling within the mesoscale watershed, develop a conceptual reservoir model, evaluate and reject the model in order to yield new insight into catchment functioning that may guide a more complete field work. The approach may be adopted as a road map in other ungauged or data sparse regions where a quick assessment of streamflow generating processes is necessary.

\section{Material and methods}

\subsection{Study area}

The study catchment is a $475 \mathrm{~km}^{2}$ sized subbasin of the Xilin river watershed which is located at approximately $43^{\circ} \mathrm{N}$ and

Published by Copernicus Publications on behalf of the European Geosciences Union. 


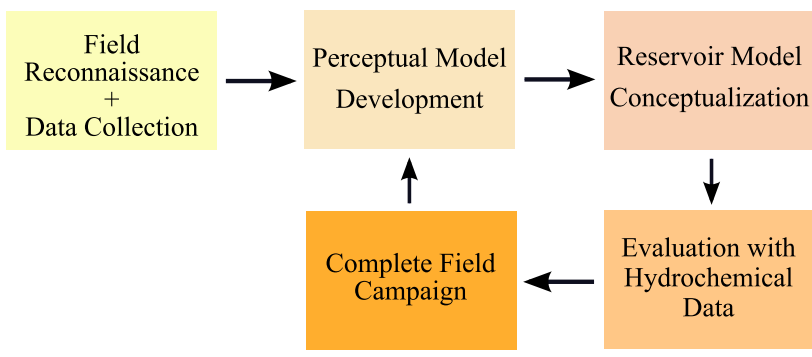

Fig. 1. Flow chart of top-down approach.

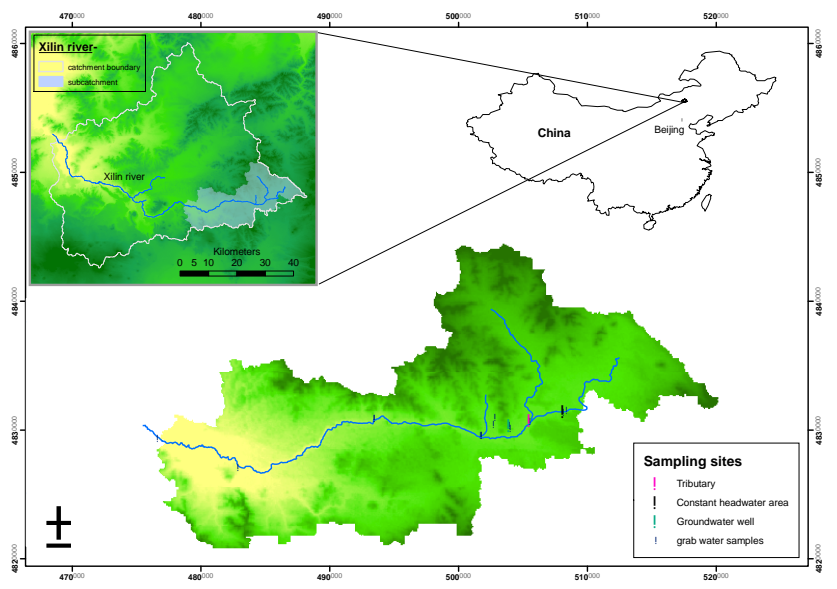

Fig. 2. Digital elevation model of the Xilin river watershed and subbasin. Inset: Xilin river location in China.

$116^{\circ} \mathrm{E}$ in the autonomous province of Inner Mongolia, China (Fig. 2). The Xilin river watershed has a size of about $10000 \mathrm{~km}^{2}$ (Tong et al., 2004) and is an inland river basin which is characterized by semiarid conditions with cold, dry winters and warm, wet summers. The mean annual precipitation is $350 \mathrm{~mm}$ but is highly variable in space and time. Chen (1988) reported annual ranges of 180 to $500 \mathrm{~mm}$, with 60 to $80 \%$ of the annual precipitation falling between June and August. The mean annual air temperature is $2^{\circ} \mathrm{C}$ with a July average of $18^{\circ} \mathrm{C}$ and a January average of $-23^{\circ} \mathrm{C}$ (Chen, 1988). Mean actual evapotranspiration during the vegetation period is larger than $90 \%$ of the precipitation (Y. Wen, personal communication) and lower throughout the rest of the year.

\subsection{Field data collection}

Snapshot sampling (Grayson et al., 1997) was used to collect hydrometric and chemical data. Grab samples of water were collected from a variety of locations at approximately the same time, and analyzed with an inductively coupled plasma - mass spectrometer (ICP-MS) for a suite of 20 major and minor chemical tracers ( $\mathrm{Li}, \mathrm{B}, \mathrm{Al}, \mathrm{V}, \mathrm{Cr}, \mathrm{Mn}, \mathrm{Fe}, \mathrm{Co}, \mathrm{Ni}, \mathrm{Cu}$, $\mathrm{Rb}, \mathrm{Sr}, \mathrm{Mo}, \mathrm{Cd}, \mathrm{Ba}, \mathrm{U}, \mathrm{Na}, \mathrm{Mg}, \mathrm{Ca}, \mathrm{K})$. Field data collection in the Xilin river watershed is limited to the time period be-
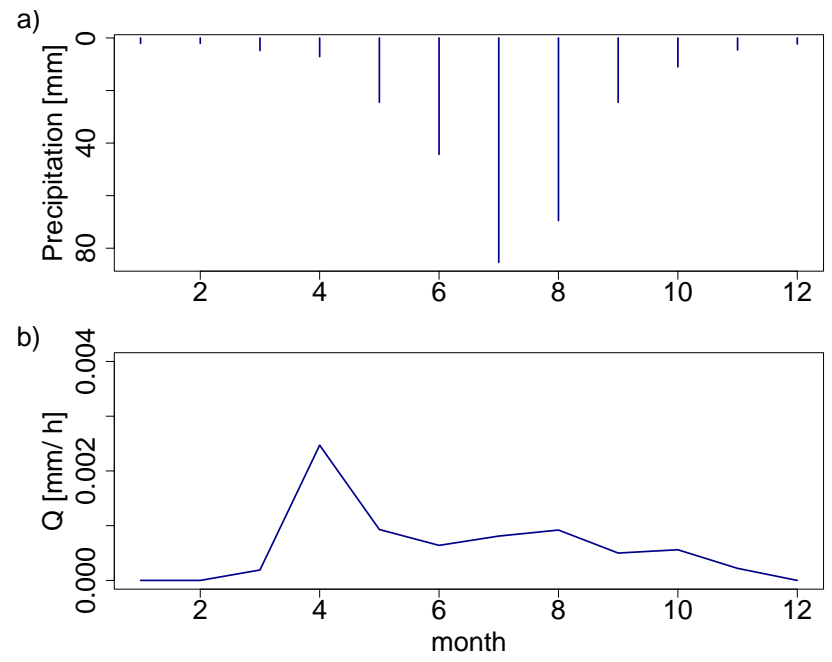

Fig. 3. Mean monthly precipitation (a) and mean monthly discharge (b) for the whole Xilin river watershed (1954-2004).

tween April and late October, while the water of the river is unfrozen. Therefore, all datasets are limited to this time period. Although initial field reconnaissance of the watershed started in 2004, we exclusively used the most detailed data set collected during the field period of 2006 for this study. We applied simple explorative data analysis to identify possible end members, as common in mixing analysis. End members are defined as source solutions that have more extreme chemical concentrations than the stream water (Christopherson and Hooper, 1992). In theory, their mixture yields the hydrochemical concentration of the water in the main stream of the catchment. The identification of end members can be used to contribute to a more complete understanding of the different processes which contribute to the generation of streamflow.

Precipitation was measured with a tipping bucket rain gauge (RM Young, Traverse City, Michigan, USA) and recorded in 10 min time steps (Ketzer et al., 2008). Evapotranspiration was assumed constant during the vegetation period and estimated as $90 \%$ of the 2006 vegetation season precipitation (Y. Wen, personal communication). The hydrograph does not reflect the annual precipitation pattern: despite low snow rates during the winter months (November through March) vernal discharge reaches highest values during the melting period, whereas the precipitation peak in June and July only results in a secondary, only minor discharge peak towards the end of the vegetation period in $\mathrm{Au}-$ gust (Fig. 3).

\subsection{Model description}

We developed a simple lumped reservoir model based on the Tank Model, to represent the different water stores (Sugawara, 1961, 1995). As in the Tank Model, each reservoir 


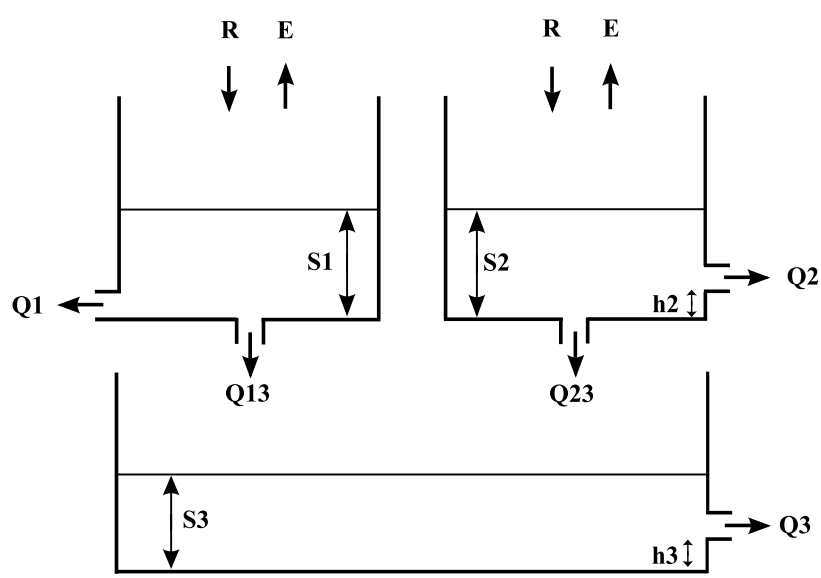

Fig. 4. Lumped conceptual model of the Xilin river catchment with $\mathrm{R}=$ rainfall, $\mathrm{E}=$ evapotranspiration, $\mathrm{Q}=$ discharge, $\mathrm{S}=$ storage depth and $\mathrm{h}=$ threshold height for water to start flowing. The discharge indices refer to the type of discharge: single number means discharge to stream, composite number means groundwater recharge.

represents a different component of the catchment. The storage depth of each reservoir is calculated as the difference between precipitation input ( $\mathrm{R}$ in $[\mathrm{mm} / \mathrm{h}])$ and loss via evapotranspiration (E in $[\mathrm{mm} / \mathrm{h}]$ ) and calculated discharge (Q in $[\mathrm{mm} / \mathrm{h}])$. The output of each reservoir is the calculated runoff. Our lumped model consists of three reservoirs: S1, S2, and S3 (Fig. 4). The reservoir model assumes a linear relationship between storage depth and output for the headwater source and a non-linear relationship for the tributary and the groundwater source. The various discharge components are calculated as follows:

Discharge to stream from headwater source (Q1)

$\mathrm{Q} 1=\mathrm{a} 1 \times(\mathrm{S} 1-\mathrm{h} 1)^{\mathrm{m} 1}$

Groundwater recharge from headwater source (Q13)

$\mathrm{Q} 13=\mathrm{a} 13 \times(\mathrm{S} 1-\mathrm{h} 13)^{\mathrm{m} 13}$

Discharge to stream from tributary $(\mathrm{Q} 2)$

$\mathrm{Q} 2=\mathrm{a} 2 \times(\mathrm{S} 2-\mathrm{h} 2)^{\mathrm{m} 2}$

Groundwater recharge from tributary (Q23)

$\mathrm{Q} 23=\mathrm{a} 23 \times(\mathrm{S} 2-\mathrm{h} 23)^{\mathrm{m} 23}$

Discharge to stream from groundwater (Q3)

$\mathrm{Q} 3=\mathrm{a} 3 \times(\mathrm{S} 3-\mathrm{h} 3)^{\mathrm{m} 3}$

where a and $\mathrm{m}$ are two calibrated conceptual model parameters which remain constant, $\mathrm{S}$ is the storage depth of the reservoir $[\mathrm{mm}], \mathrm{h}$ is the threshold height for water to start flowing [mm] and 1, 2 and 3 indicate the different reservoirs. Total stream discharge is calculated as the sum of the discharge from the headwater source area, the tributary and the

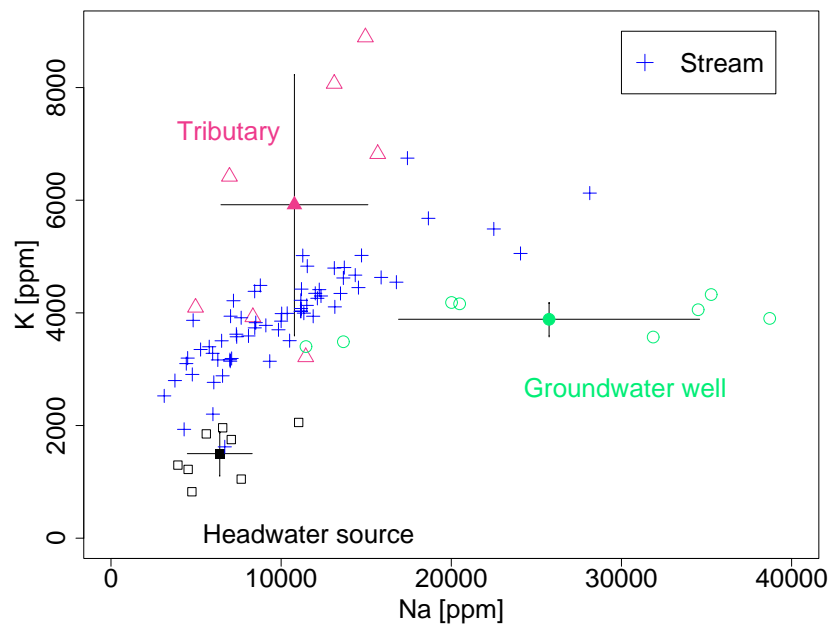

Fig. 5. Bivariate plot of $\mathrm{Na}$ and $\mathrm{K}$ concentration of water samples of end members and the main stream, bold symbols represent the median and $95 \%$ confidence intervals of the end members.

groundwater, each weighted by contributing area. The area weight representing the headwater and tributary sources was assumed to be equivalent to the land surface areas of each ( 0.18 and 0.82 of the total area, respectively). We further assumed that the contributing area of the groundwater source was equivalent to the entire catchment area, giving it a weight of 1.0 .

\section{Top-down approach}

In the following we describe our top-down approach that consists of five steps (Fig. 1). This approach generally follows the "downward route" - concept as introduced by Klemeš (1983), from field data to conceptual model development and testing.

\subsection{Step 1: Field reconnaissance and data collection}

Initial field reconnaissance of the Xilin River Basin started in 2004 and was focused on discharge measurements and grab water collection after the snapshot sampling method (Grayson et al., 1997). Specifications for data collection are given in Sect. 2.2. A detailed, for our purposes useful dataset consisting of discharge and precipitation measurements as well as hydrochemical information of various water sources, could be established during the field season of 2006 .

\subsection{Step 2: Perceptual model development}

Bivariate plots of $\mathrm{Na}$ and $\mathrm{K}$ concentration were used to identify potential end members of streamflow (Fig. 5). Na and K have widely been used for hydrograph separation (e.g. Hill, 1993; Elsenbeer et al., 1995; Neal et al., 1997) and were chosen for these plots because they most clearly identified water 


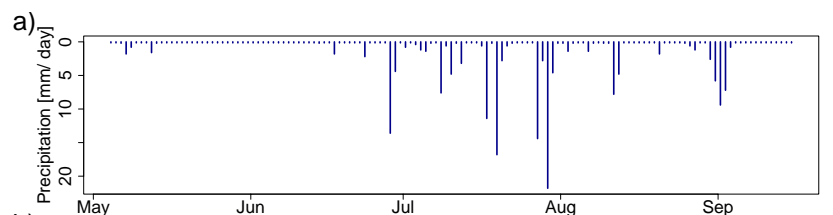

b)

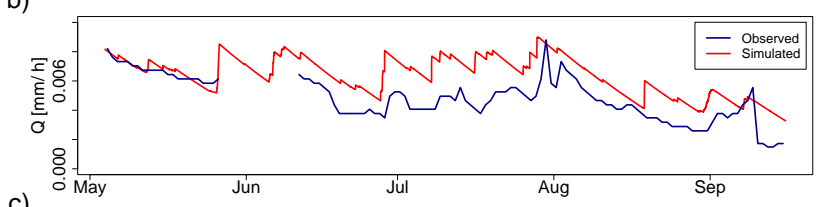

c)

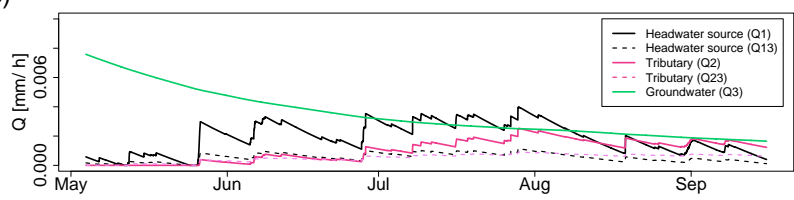

Fig. 6. Precipitation (a), observed and simulated hydrographs of the stream (b) and simulated hydrographs of the end members (c) of the 2006 vegetation period.

sources. Weekly streamflow, a $4 \mathrm{~m}$ deep groundwater well, a tributary and streamwater at the headwater source area taken during the field season 2006 are presented in Fig. 5. The headwater source area, the groundwater well and the tributary were identified as end members which serve as anchor points for construction of the conceptual reservoir model (Fig. 4). The stream concentrations are low at the beginning of the season, increase over the course of the season, peak in August and slightly decrease in September (Figs. 5 and 7). These data suggest a perceptual model of discharge development where stream flow is initially dominated by the headwater source. As the vegetation growth season progresses with increased rainfall and evapotranspiration contributions of water from the ephemeral tributary and the groundwater source begin to increase, until in September when the tributary runs dry and the wetland area at the headwater source is saturated with water and again turns into the dominant contributor.

\subsection{Step 3: Reservoir model conceptualization}

Based on the end members, the conceptual reservoir model was developed to capture the evolution of stream water sources as consistent with our perceptual model, and the data we used to develop it. The model was applied to simulate total stream discharge as well as the discharges of each of the end members (Fig. 6). Calibration was conducted on a visual basis of simulated and observed discharges in the main stream (Fig. 6b). The parameter values resulting from the calibration exercise are listed in Table 1. The model captured the downward trend of the discharge at the beginning of the summer season and the major flow peaks, although the presented calibration includes a general overestimation of discharge throughout the growing season. Despite the overesti-
Table 1. Values of model parameters for discharge components of the conceptual reservoir model: a and $\mathrm{m}$ are two conceptual model parameters, $\mathrm{S}$ is the storage depth of the reservoir and $\mathrm{h}$ is the threshold height for water to start flowing. Values were derived from manual model calibration.

\begin{tabular}{lllllll}
\hline & Unit & $\mathrm{Q} 1$ & $\mathrm{Q} 13$ & $\mathrm{Q} 2$ & $\mathrm{Q} 23$ & $\mathrm{Q} 3$ \\
\hline $\mathrm{a}$ & - & 0.007 & 0.0002 & 0.00001 & 0.00002 & 0.001 \\
Initial S & $\mathrm{mm}$ & 4.5 & 4.5 & 0 & 0 & 11.5 \\
$\mathrm{~h}$ & $\mathrm{~mm}$ & 0 & 0 & 10 & 0 & 2 \\
$\mathrm{~m}$ & - & 1 & 1 & 1.5 & 1 & 2 \\
\hline
\end{tabular}

mation, the simulated storm hydrographs of the end members clearly show the trend of the observed hydrographs: increase of the constant headwater source throughout the season and start of flow of the ephemeral tributary at the beginning of June (Fig. 6c). The poor performance in the recession of the hydrographs is likely attributable to the linear storage concept. The model was able to produce a better fit for the discharge during the growing season, but this improvement resulted in a deterioration in the fit during the snowmelt recession. While accomplished without the aid of an automatic multi-criteria calibration procedure, this inability to capture both the snowmelt recession and the growing season discharge suggests either a structural flaw or the presence of an unidentified end member.

3.4 Step 4: Evaluation using hydrochemical data and rejection of initial model

The key interest in this study lies in identifying the dominant runoff producing processes. Therefore, the following questions arise: Why does the model work during the snowmelt recession and not during the rest of the season? Is the groundwater really the source for the receding hydrograph during the spring period and does the ephemeral tributary account for the minor discharge peak in the late vegetation season (Fig. 6c)?

In this top down approach, where quick diagnosis of catchment functioning is the focal point, we view the step of model evaluation and rejection as a crucial step for any further model development. At first glance, the most compelling reason for the inability to capture the discharge during the vegetation period is a structural flaw resulting in an underestimation of actual evapotranspiration during the vegetation period (Fig. 6b) since simulated and observed discharge match during the period of snowmelt at the start of the summer season but reveal overestimation of simulated discharge during the rest of the summer season. However, the simulated discharge in Fig. $6 \mathrm{~b}$ is the sum of the discharges of the three different end members headwater source, tributary and groundwater in Fig. 6c. The apportionment of the discharges of our three 
Table 2. Mean concentrations of Sodium (Na) and Potassium (K) in water of the three end members which were used as input parameters for model evaluation, and modified values of the groundwater source as input for the virtual experiment based on model re-evaluation.

\begin{tabular}{llllll}
\hline & Unit & $\begin{array}{l}\text { Headwater } \\
\text { source }\end{array}$ & Tributary & Groundwater & $\begin{array}{l}\text { Modified } \\
\text { groundwater }\end{array}$ \\
\hline $\mathrm{Na}$ & $\mathrm{ppm}$ & 5601.5 & 10780.7 & 22883.6 & 1000.0 \\
$\mathrm{~K}$ & $\mathrm{ppm}$ & 1361.2 & 5919.8 & 3719.8 & 1000.0 \\
\hline
\end{tabular}

different end members in the latter figure shows that the simulated discharge during spring is mainly controlled by the groundwater hydrograph. The time series of the $\mathrm{K}$ and $\mathrm{Na}$ concentrations (Figs. 5 and 7), however, suggest a dominant discharge contributing role of the headwater source at the beginning of the season. It is this contradiction that leads us to the assumption that our model is structurally correct, but that our data do not capture the true end members of the system.

We then utilized chemical data for evaluation of our conceptual reservoir model. The seasonal means of $\mathrm{Na}$ and $\mathrm{K}$ of each end member were used as inputs (Table 2). The $\mathrm{K}$ and $\mathrm{Na}$ concentrations of the stream were simulated as the sum of the area weighted discharges, as defined previously, of the end members over the course of the vegetation period. Figure 7 presents the simulated seasonal stream concentration which shows the converse trend of the observed bivariate plot with high concentrations at the beginning of the season, decreasing concentration throughout the season and again increasing concentrations at the end of the season.

Since the model does not reflect the expected chemical behavior we have to reject our initial model perception. We assume that our model does not capture the important end members that contribute to stream flow. Virtual experiments were used in an initial exploration of these missing links in our conceptual model.

As a first step, it is important to recognize that our conceptual reservoir model relies upon the assumption that the mean values of $\mathrm{Na}$ and $\mathrm{K}$ were representative of the end member concentrations. This simplification was initially used because we lacked any compelling evidence for another choice, but it is clear that the end member chemistry will, in fact, vary throughout the measured range. As an initial re-assessment of the model we focus upon this range of variation, rather than the model structure itself, and evaluate how changing the end member concentrations, within measured ranges, might result in changes to the mixture chemistry. Specifically, we adjusted the groundwater end member positions at the beginning of the season to smaller values to account for poorly defined water sources, but again did not change the model structure or parameterization (Table 2). The adjustment of the end member input concentrations yields the possible chemical characteristic of a newly

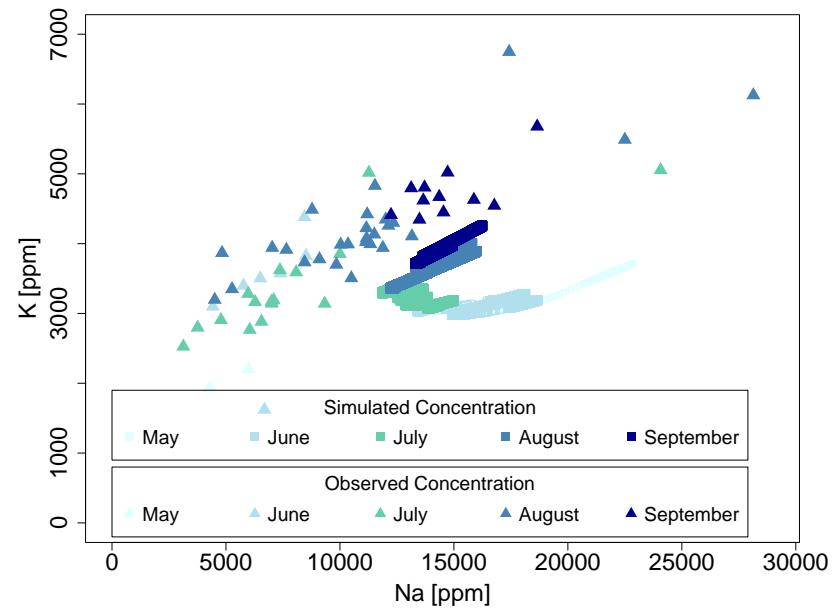

Fig. 7. Bivariate plot of observed and simulated $\mathrm{Na}$ and $\mathrm{K}$ concentration of the stream in 2006 following the initial model.

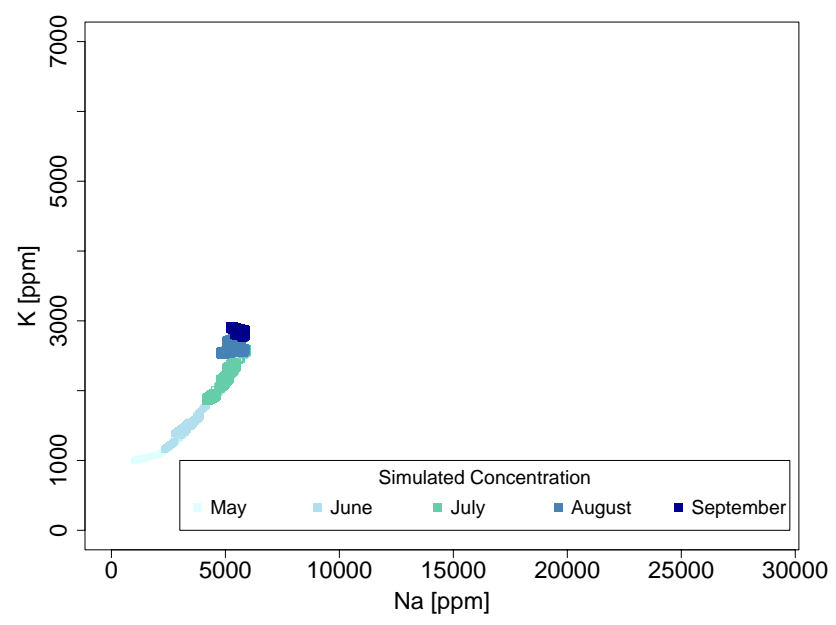

Fig. 8. Bivariate plot of simulated $\mathrm{Na}$ and $\mathrm{K}$ concentration of the stream in 2006 with modified groundwater concentration input.

defined end member because the simulation of modified endmembers does capture the trend of the observed stream data with low values at the beginning of the season with increasing values over the course of the season (Fig. 8). The modification suggests the existence of a new end member with low concentrations. The most likely candidate for this additional end member is snow melt, which will now guide additional field work in this iterative approach to watershed diagnosis.

\subsection{Step 5: Real field campaign}

Our results of the virtual experiments lead us to the conclusion that a water source with low $\mathrm{K}$ and $\mathrm{Na}$ concentrations is a missing end member in our conceptual model as well as another end member with high concentrations. Snowmelt and an additional groundwater source would meet these 
requirements. These theories will guide further field campaigns where we will include snowmelt and deeper groundwater sources in our sampling scheme.

\section{Conclusions}

Large, poorly gauged basins present a major research challenge for understanding catchment processes (Sivapalan, 2003). Our study area, the Xilin river catchment, is such a poorly gauged basin. Initial field reconnaissance of the watershed started in 2004 and more detailed data collection during the vegetation periods focusing on identification of end members that control stream generation processes followed in 2006. Attempts to use these data in hydrologic model development have failed so far (Schneider et al., 2007). This is likely due to the fact that the major discharge peak is created by snowmelt during spring and only a secondary, minor discharge peak occurs during the vegetation period in the summer months. The top-down approach presented in this study, starting at first field reconnaissance, to the perceptual model and conceptualized model to rejection and revision, has been implemented in an effort to learn from wrong predictions at an early stage of catchment gauging and understanding as demanded by Sivapalan (2003). It led us from almost no catchment understanding to the preliminary identification of control variables on flow and an assessment of the effectiveness of our sampling design. Our next steps are to conduct new sampling to define a likely snowmelt and deeper groundwater aquifer end members responsible for flow generation.

Acknowledgements. The authors are grateful to the Deutsche Forschungsgemeinschaft (DFG) for their generous funding (FG 536). Technical and logistical support from the Inner Mongolia Grassland Ecosystem Research Station (IMGERS) and the administrative support from Yuandi Zhu is also acknowledged. We thank Christian Bernhofer and Bettina Ketzer from TU Dresden for providing the precipitation data.

Edited by: F. Portmann, K. Berkhoff, and M. Hunger

Reviewed by: two anonymous referees and the editors

\section{References}

Chen, Z.: Topography and climate of the Xilin river basin (in Chinese with English abstract), Inner Mongolia Ecosystem Grassland Station, Research on Grassland Ecosystems, 3, 13-22, Beijing, Science Press. 1988.

Christopherson, N. and Hooper, R. P.: Multivariate analysis of stream water chemical data: The use of principal components analysis for the end-member mixing problem, Water Resour. Res., 28, 99-107, 1992.

Elsenbeer, H. and Lorieri, D.: Mixing model approaches to estimate storm flow sources in an overland flow-dominated tropical rain forest catchment, Water Resour. Res., 31(9), 2267-2278, 1995.

Grayson, R. B., Gippel, C. J., Finlayson, B. L., and Hart, B. T.: Catchment-wide impacts on water quality: the use of 'snapshot' sampling during stable flow, J. Hydrol., 199, 121-134, 1997.

Hill, A. R.: Base cation chemistry of storm runoff in a forested headwater wetland, Water Resour. Res., 29(8), 2663-2675, 1993.

Ketzer, B., Bernhofer, C., and Liu, H.: Surface characteristics of grasslands in Inner Mongolia as detected by micrometeorological measurements. Int. J. Biometeorol, in press, doi:10.1007/s00484-008-0145-5b, 2008.

Klemeš, V.: Conceptualization and scale in hydrology, J. Hydrol., 65, 1-23, 1983.

Neal, C., Wilkinson, J. Neal, M., Harrow, M., Wickham, H., Hill, L., and Morfitt, C.: The hydrochemistry of the headwaters of the River Severn, Plynlimon, Hydrol. Earth Syst. Sci., 3, 687-696, 1997, http://www.hydrol-earth-syst-sci.net/3/687/1997/.

Schneider, K., Ketzer, B., Breuer, L., Vaché, K. B., Bernhofer, C., and Frede, H.-G.: Evaluation of evapotranspiration methods for model validation in a semi-arid watershed in northern China, Adv. Geosci., 11, 37-42, 2007, http://www.adv-geosci.net/11/37/2007/.

Seibert, J. and McDonnell, J.J.: On the dialog between experimentalists and modeler in catchment hydrology: Use of soft data for multicriteria model calibration, Water Resour. Res., 38(11), 1241, doi:10.1029/2001WR000978, 2002.

Sivapalan, M.: Predictions in ungauged basins: a grand challenge in theoretical hydrology, Hydrol. Process., 17, 3163-3170, 2003.

Sugawara, M.: On the analysis of runoff structure about several Japanese rivers, Jap. J. Geophys., 2(4), 1-76, 1961.

Sugawara, M.: Tank Model, in: Computer Models of Watershed Hydrology, edited by: Singh, V. P., 1995.

Tong, C., Wu, J., Yong, S, Yang, J., and Yong, W.: A landscapescale assessment of steppe degradation in the Xilin River Basin, Inner Mongolia, China, J. Arid Environ., 59, 133-149, 2004. 